Proceedings of the 10th International Ruminant Reproduction Symposium (IRRS 2018); Foz do Iguaçu, PR, Brazil, September 16th to 20th, 2018.

\title{
Modeling early embryo-maternal interactions in vitro
}

\author{
Jennifer Schoen*, Shuai Chen \\ Institute of Reproductive Biology, Leibniz Institute for Farm Animal Biology (FBN), Dummerstorf, Germany.
}

\begin{abstract}
Environmental conditions experienced during early embryonic development influence growth, metabolism, and gene expression of the embryo as well as the epigenetic profile of the offspring. The environment of the early embryo consists of the luminal fluid within the oviduct and uterus and the epithelial cells composing this fluid. Whether the embryo is able to shape its own microenvironment by interacting with the epithelial lining of the oviduct/uterus and which factors potentially interfere with or regulate these interactions remains to be elucidated. As early embryonic signals and the respective maternal responses are subtle and local events, it is challenging to study them in vivo. Therefore, adequate in vitro-models optimally mimicking the contact zone between the maternal reproductive tract and the early embryo are needed to a) elucidate basic mechanisms involved in early embryonic development and b) reduce the number of experimental animals used for such studies. Functional epithelial cells are generally defined by a polarized distribution of organelles and proteins. Proper polarization is tightly connected with physiological cell behavior and in vivo-like reactivity of the epithelium. Therefore, this review summarizes current strategies for in vitro preservation of epithelial cell polarity. It presents recent advances in 3D culture of female reproductive tract epithelia and embryo-epithelial cocultures. A special emphasis is set on compartmentalized culture systems, powerful tools for studying early embryo-maternal interactions in vitro. In such systems, cultured epithelial cells are manipulable from their basolateral as well as their apical cell pole, allowing concomitant application of embryonic as well as maternal effectors from the appropriate cellular compartment.
\end{abstract}

Keywords: embryo-maternal interactions, endometrium, oviduct, three dimensional cell culture models.

\section{Introduction}

Early embryos of eutherian mammals reside within the oviduct (species-specific up to the 4-cell, 8cell, morula or blastocyst stage) before they transition into the uterus. It is now well established that the environmental conditions experienced during early embryonic development (zygote to blastocyst stage) influence growth, metabolism, and gene expression of the embryo as well as the epigenetic profile of the offspring (recently reviewed by Fazeli and Holt, 2016; Rizos et al., 2017).

So far, clear evidence is given for a mutual, reciprocal interaction between the female reproductive tract (FRT) and the developing conceptus during maternal recognition of pregnancy and implantation. However, the biological relevance of earlier interactions of the embryo with the upper FRT is still a matter of debate.

Studies in litter bearing species like pigs and mice show that the oviduct responds to preimplantation embryos, long before the embryonic signal for maternal recognition of pregnancy (Lee et al., 2002; Alminana et al., 2012; Li et al., 2015). In the monovulatory cow, where only one single embryo resides in the oviduct, this could not be confirmed in vivo at the transcriptomic level (Maillo et al., 2015), but first hints exist for an early embryonic influence on the oviduct fluid proteome in this species (Maillo et al., 2016). There is clear in vivo evidence for early embryo-maternal communication in another monovulatory species, the horse, where embryonic prostaglandin E2 causes relaxation of the oviductal isthmus and allows selective transport of the embryo to the uterus (Weber et al., 1991; Freeman et al., 1992). Differential transcriptomic profiles between pregnant and non-pregnant oviducts also suggest an impact of one single early embryo on the innate immune response in the equine FRT (Smits et al., 2016).

However, whether the embryo is actually able to shape its own microenvironment by interacting with the epithelial lining of the oviduct/uterus and which factors potentially interfere with or regulate this fine-tuned interactome (Fazeli, 2011) remains to be elucidated.

As early embryo-maternal interactions are presumably subtle and local events, they are challenging to study in vivo (not only, but especially in monovulatory species), both from a technical and an ethical point of view. Biological variation, very limited numbers of possible replicates and the unfavorable signal-to-noise ratio might hamper the success of such in vivo studies.

Therefore, adequate in vitro-models optimally mimicking the contact zone between the maternal reproductive tract and the early embryo could help to elucidate basic mechanisms involved in early embryonic development and programming. At the same time such models reduce the number of experimental animals needed for basic research and might proof useful also for reproductive toxicity testing (Simintiras and Sturmey, 2017). 


\section{The environment of the early embryo}

The environment of the early embryo consists of the luminal fluid within the FRT and the epithelial cells composing this fluid.

It is suggested that the oviduct and uterine luminal fluids represent the optimal milieu for the early embryo. Its basic composition has been analyzed with respect to protein composition, ion content and energy substrates using in situ and ex vivo techniques (reviewed in Leese et al., 2008). Differences in the fluid composition have been documented regarding the estrous cycle stage and sampling region. However, the mechanisms of oviductal and uterine fluid formation and its regulation are far from being understood.

The epithelial cells assembling the luminal surface of the oviduct and uterus compose this fluid in accordance to the developmental needs of the embryo (Absalon-Medina et al., 2014) and directly get in contact with the early embryo.

This contact zone is a simple epithelium which not only nourishes the early embryo but also provides protection from or clearance of unfavorable molecules and (in case of the oviduct) transport of the embryo towards the uterus.

\section{Epithelia of the FRT: developmental origin and structural hallmarks}

Oviduct and uterus both derive from a pair of Mullerian ducts (MDs), which consists of three elements: an inner epithelium layer, surrounding mesenchyme, and the external Mullerian coelomic epithelium. During MD development, the opening cranial end forms into the oviduct, and the caudal ends of left and right MD fuse and give rise to the uterus. Epithelia in the oviduct and uterus both develop from the MD epithelium, while the stromal compartment of uterus evolves from the MD-surrounding mesenchyme (Kurita, 2011).

Epithelia are generally defined by a polarized distribution of organelles and proteins within each cell. The paracellular space between adjacent epithelial cells is sealed by cell-cell junctions at the apical part of the lateral plasma membrane. Especially tight junctions are essential for epithelial polarity and functionality as they form both a paracellular barrier (regulating selective paracellular permeability) as well as a barrier within the membrane which restricts the exchange of membrane components between apical and basolateral cell surface domains. In recent years it became evident that beside their role as simple diffusion barriers, tight junctions are cellular signaling platforms which are regulated by diverse physiological and pathological stimuli (reviewed in (Zihni et al., 2016). Loss of cellular polarity, in turn, is a pathological condition frequently seen in cancer development, which alters specific cell functions and responsiveness to external signaling events (Ellenbroek et al., 2012).

The basal part of the cell membrane of an epithelial cell is attached to the basement membrane, which separates the epithelium from the underlying connective tissue. With this basolateral cell pole, it takes in systemic effector molecules and nutrients as well as molecules secreted by the connective tissue. In contrast, the contact to gametes or embryos takes place on the apical surface of the cell, which is morphologically and functionally different from its basolateral counterpart in terms of membrane properties and abundance of receptor molecules.

Therefore, proper polarization of the epithelial cells in the FRT is tightly connected with their physiological behavior and in vivo-like reactivity towards systemic maternal as well as embryonic stimuli.

\section{Modelling the contact zone: oviductal and uterine epithelial cells in vitro}

Maintenance of epithelial polarity during culture is an important prerequisite for in vitro investigations concerning the fine-tuned interactions possibly taking place between the early embryo and the maternal organism.

Under standard culture conditions (2D, adherent on cell culture plastic ware), which are most frequently used to explore embryo-maternal interactions in vitro, epithelial cells (primary or cell lines) from the FRT attach to the plastic surface and are submerged in medium. Even if cells build cell-cell contacts and a certain level of cellular polarization under such conditions, they receive nutrition from the apical pole. This leads to rapid adaptation processes within the cells and to marked changes in their morphological and functional integrity (Fig. 1A). Polarization, expression of marker genes and ciliation get lost (Danesh et al., 2016). A well-known example for the loss of marker gene expression during in vitro culture is the oviductal glycoprotein 1 (OVGP1), one of the most abundant glycoproteins in the oviduct of most mammals (Coy et al., 2008). Under 2D culture conditions, OVGP1 is promptly down-regulated and cannot be triggered by ovarian steroids anymore (Briton-Jones et al., 2002, 2004; Schoen et al., 2008; Danesh et al., 2016).

Cell culture conditions preserving epithelial cell polarity in vitro

\section{Suspension culture}

Suspension culture (Fig. 1B) is frequently used for primary oviduct epithelial cells (OEC), especially for analysis of sperm binding in mammalian species (De Pauw et al., 2002; Waberski et al., 2005; Henry et al., 2015). Cells are obtained by squeezing out or scraping off the oviduct epithelium, and later maintained in suspension culture dishes as cell clusters (also termed explants) with their cilia directed outwards. Suspension culture is a particularly useful tool for short-term experiments as it preserves oviduct specific characteristics for approximately $12 \mathrm{~h}$ before first signs of de-differentiation are observed (Rottmayer et al., 2006). 


\section{D Organoids}

Epithelial cells cultured in extracellular matrix (ECM) substitutes can form three dimensional structures with a lumen (Fig. 1C). An organoid culture system from clonal cells was established from the human oviduct, which showed fully in vivo-like epithelial differentiation including OVGP1 expression (Kessler et al., 2015). Likewise, three dimensional human glandular endometrial cultures were recently developed, leading to highly differentiated, hormoneresponsive organoids, which secreted uterine marker proteins like glycodelin and osteopontin (Turco et al., 2017). In these models stemness was maintained within the cell population and therefore allowed long- term culture. Differentiation is induced via exogenous factors. Gland-like endometrial spheroids have also been used to study human endometrium-trophoblast interaction and trophoblast invasion (Buck et al., 2015). However, manipulation of the organoid lumen, e.g. applying an embryo or embryonic effector molecules on the apical cell pole, is not possible. Yet such organoid cultures enable propagation of differentiated FRT epithelia in vitro (e.g. from one individual). Organoid cultures represent selforganizing 3D systems which are genetically stable and contain progenitor and/or stem cells as well as differentiated cells. Therefore, they can be used as a substitute for freshly isolated primary cells in other culture systems.
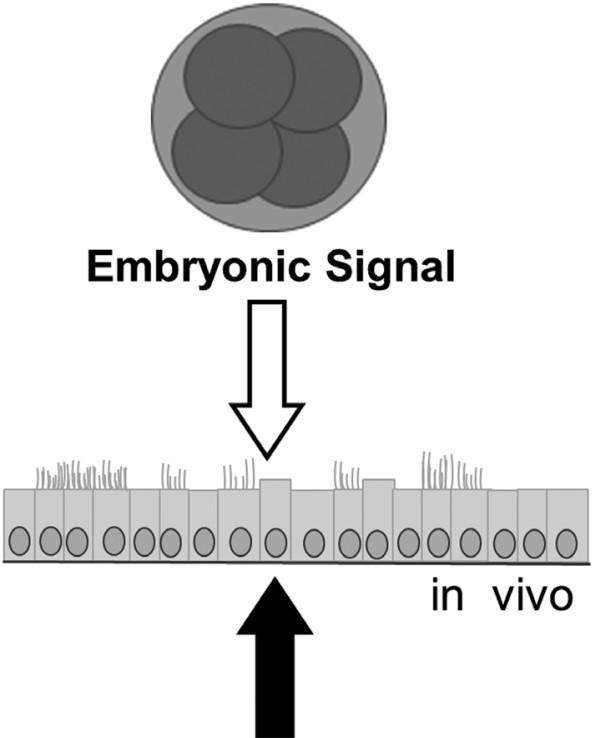

\section{Nutrition}

A

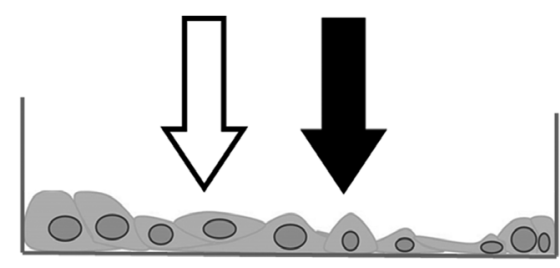

B
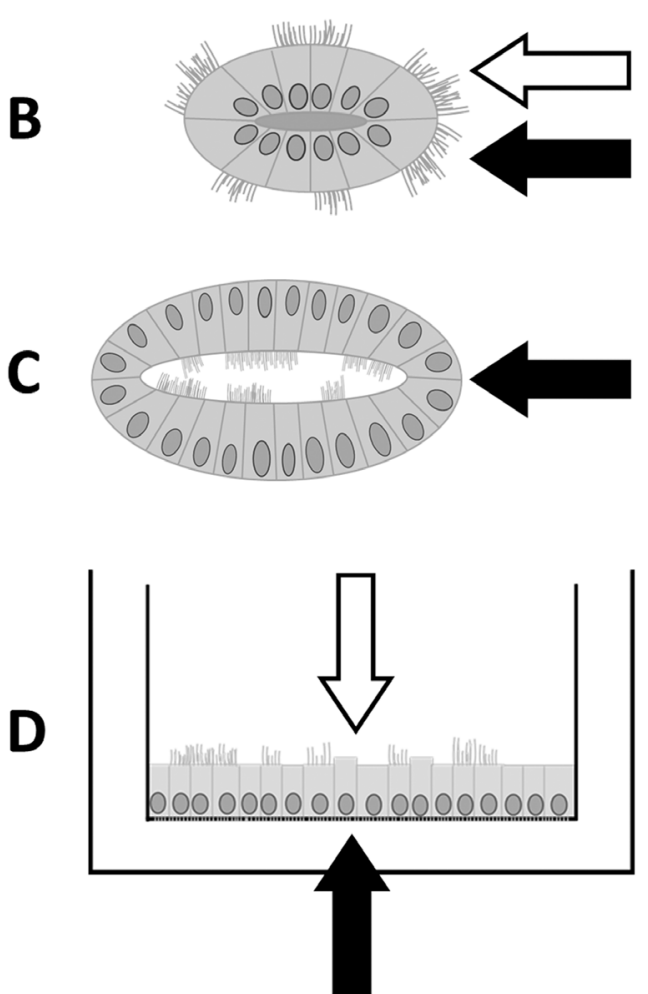

Figure 1. Schematic illustration of possible reception routes for embryonic signals and nutrition in different culture systems of epithelial cells. (A) Standard 2D adherent submerged culture; embryonic signals and nutrition from apical side. (B) Epithelial sphere in suspension culture; signals and nutrition from outside of the sphere (apical epithelial cell pole). (C) Epithelial 3D organoid; nutrition is provided from outside the organoid; embryonic signal is not applicable. (D) Compartmentalized culture system; nutrition from the basolateral side, embryonic signal could be given from the apical side.

\section{Compartmentalized culture systems}

In compartmentalized culture systems, cells are grown in inserts on either porous membranes or scaffolds (Fig. 1D). Placing the insert into the cell culture medium mimics the in vivo nutrient supply from the basolateral side of the cell, and thereby supports epithelial differentiation and polarization. The compartmentalized system can be used to grow cells submerged (liquid-liquid interface) with either the same or two different media in the basolateral and apical compartment (e.g. creating a serum gradient over the 
membrane). Porous filter supports can also be used to grow FRT epithelia at the air-liquid interface (ALI), i.e. with no medium in the apical compartment. The ALI method is primarily known from differentiated longterm cultures of skin and airway epithelia. When applied to FRT epithelia, ALI culture systems engendered excellent long-term differentiation of oviduct (Levanon et al., 2010; Miessen et al., 2011; Gualtieri et al., 2012) and uterine epithelial cells (Munson et al., 1990; Classen-Linke et al., 1997). In general, as known for airway epithelia, ALI culture seems to better support differentiation of FRT epithelia than submerged conditions. Furthermore, ALI models allow acquisition and analysis of the luminal fluid created by the epithelia. Initial analysis of oviductal fluid surrogates obtained from ALI cultures showed apparent similarities to oviductal fluid in vivo (Simintiras et al., 2016; Chen et al., 2017). This makes the ALI approach a promising tool to investigate effectors regulating or modifying the environment of the early embryo.

In compartmentalized culture systems, cell polarization can be further enhanced by coating the membrane or scaffold with ECM components like collagens (Munson et al., 1990; Chen et al., 2017). Especially collagen IV, a structural protein present in the apical lamina densa of the basement membrane, could facilitate the initial attachment rate of isolated cells during seeding and therefore prevent dedifferentiation due to excessive proliferation (Aumailley and Timpl, 1986). Also conditioning the basolateral medium with homo- or heterologous fibroblasts enhances the structural differentiation of the cultured epithelial cells (Munson et al., 1990; Ostrowski and Nettesheim, 1995; Miessen et al., 2011).

\section{D models combining epithelial and stromal cells}

Stromal cells regulate cell fate, morphology, and function of epithelia through epithelialmesenchymal interactions (Cunha et al., 1985; Kurita et al., 2001). Interactions between epithelial and stromal cells are evident in the oviduct (Umezu and Tomooka, 2004) as well as in the uterus, where they have been extensively studied in human models for decidualization and embryo invasion (reviewed in Weimar et al., 2013). Stromal cells seem to translate systemic signals within the maternal organism (e.g. from steroid hormones) and to modulate their effect on the epithelial lining (Pierro et al., 2001; Qi et al., 2012).

Stromal cells can be co-cultured with epithelial cells in compartmentalized culture systems with or without ECM resembling scaffolds (e.g. hydrogel, agarose or matrigel; Fig. 2). While 3D models of the oviductal or luminal endometrial epithelium with the underlying stroma can relatively easily be constructed (Arnold et al., 2001; Simintiras et al., 2016; Fig. 2A, B), modeling the endometrium with both its glandular and luminal epithelium in $3 \mathrm{D}$ is a more complex endeavor.
In contrast to the luminal epithelium, the glandular endometrial epithelium finds its niche within the interstitial tissue (Fig. 2C). To our knowledge, there is only one report documenting the capability of uterine epithelial cells to form both the endometrial luminal epithelium as well as glands in vitro. Primary epithelial endometrium cells were co-cultured with stromal cells seeded in fibrin-agarose and gland formation occurred spontaneously (Wang et al., 2012).

More recent epithelial-stromal co-culture models are based on ex vivo ECM scaffolds as the decellularized endometrium (Olalekan et al., 2017) or novel artificial scaffold structures (MacKintosh et al., 2015) which provide a more in vivo-like 3D environment for the stromal cells.

\section{Perfused culture systems and microfluidic devices}

The FRT epithelium of most mammalian species undergoes dramatic morphological and functional changes throughout the estrous cycle. In the luteal phase (progesterone dominance), the epithelium exhibits a regressed status; conversely, cells re-enter proliferative status in the follicular phase (estradiol dominance), including a rise in epithelium height and increased secretory activity.

However, the exact and time resolved impact of hormones (as well as many other dynamic systemic maternal cues) on luminal fluid formation and epithelium responsiveness to embryonic signals are not elucidated yet. Even if different stages of the estrus cycle can be mimicked in compartmentalized models of the FRT epithelium (Chen et al., 2013), these systems are still static. Devices which allow constant perfusion of the cell culture vessel therefore provide much better options for modeling the dynamic changes induced by maternal cues and to elucidate their effects on the embryonic environment and the embryo itself. Perfusion approaches were already used to model FRT epithelia, and were proven to enhance structural differentiation (Reischl et al., 1999). Lately, new dynamic culture systems, which enable long-term maintenance of differentiated and hormone responsive epithelia, have been established. An organ-on-a-chip model of the bovine oviduct (suitable for live cell imaging) recapitulates the oviduct epithelium over extended culture periods (up to six weeks). In co-culture experiments, epithelial interactions with sperm and oocytes as well as fertilization events were observed (Ferraz et al., 2017). Beyond that, organ modules of the murine ovary, fallopian tube, uterus, cervix and liver, with a sustained circulating flow between all tissues, were recently coupled in a multiple unit microfluidic platform. This system simulated not only the female reproductive tract, but also the endocrine loops between different organs (Xiao et al., 2017). In the era of 3D (bio-)printing, these approaches surely represent the next generation of in vitro models for studying early embryo-maternal interactions. 

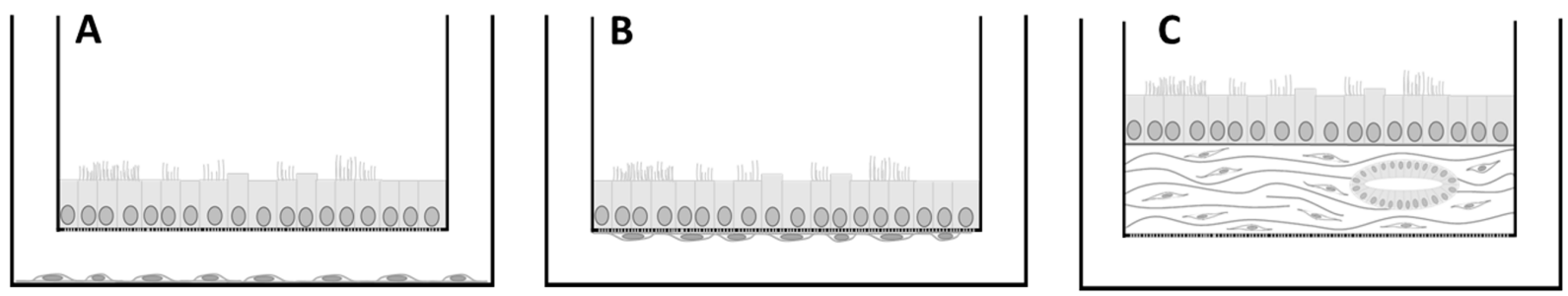

Figure 2. Schematic illustration of strategies for co-culturing stromal cells with FRT epithelial cells in compartmentalized culture systems. (A, B) Stromal and epithelial cells grown in separate compartments. (A) Stromal cells seeded in the basal culture dish. No direct epithelial-stromal cell contact; (B) Stromal cells seeded on the basal side of the insert directly beneath epithelial cells; (C) Stromal and epithelial cells within the same compartment. Stromal cells embedded in ECM support, which may permit the formation of glandular structures.

\section{Co-culture of embryos with epithelia of the FRT}

FRT epithelial cells cultured under standard 2D submerged conditions were widely used as feeder layers to improve IVP outcomes and showed a positive effect on in vitro embryo quality (Locatelli et al., 2005; Cordova et al., 2012, 2014; Schmaltz-Panneau et al., 2015). In terms of their embryo supporting capacity, however, no difference was detected between oviduct and uterine epithelial cells and oviduct stromal cells (Goff and Smith, 1998). Feeder origin also had no influence on bovine embryonic development and transcriptome when bovine oviduct epithelial cells were compared with a primate kidney cell line as feeder layer (Carvalho et al., 2017). In recent years, co-cultures have also been applied to examine early embryo-maternal dialogue. In several studies bovine embryos were cocultured with OEC to mimic the maternal environment in vitro. These experiments demonstrated bi-directional responses at the transcriptional level from both the maternal and embryo side (Schmaltz-Panneau et al., 2014; Garcia et al., 2017). However, OEC were subjected to multiple embryos and/or prolonged coincubation, which does not ideally imitate the in vivo situation in the monovulatory cow.

Taking advantage of the ALI approach (see paragraph compartmentalized culture systems), coculture experiments for the first time demonstrated embryo development on OEC up to the blastocyst stage without supplementation of any embryo culture medium (Chen et al., 2017). However, more in vivo-like mRNA expression of bovine embryos could not be proven as a result of co-culture (van der Weijden et al., 2017). We deduce that to enhance embryo quality in co-culture including a dynamic hormonal stimulation procedure might be necessary to better mimic the in vivo oviductal environment.

\section{Conclusion}

Depending on the researcher's specific scientific question, different culture models are available to reconstruct the upper FRT in vitro, either for the short or long term. In compartmentalized culture systems, epithelia are manipulable from their basolateral as well as apical surface, allowing co-culture of embryos/zygotes on the apical and concomitant application of maternal effectors to the basolateral compartment. This makes them powerful tools for studying early embryo-maternal interactions. Stromal cells and ECM components can be incorporated, which is of special interest for modeling the endometrium in vitro. Considering that the oviduct and uterus are highly dynamic, hormone responsive organs, perfused culture systems or microfluidic devices allow a more in vivolike recapitulation of the early embryonic environment. The recent advances achieved in these model systems provide the basis for deciphering the possibly fine-tuned interactions between the single early embryo and the maternal organism as well as their effects on offspring development and health.

\section{References}

Absalon-Medina VA, Butler WR, Gilbert RO. 2014. Preimplantation embryo metabolism and culture systems: experience from domestic animals and clinical implications. J Assist Reprod Genet, 31:393-409.

Alminana C, Heath PR, Wilkinson S, SanchezOsorio J, Cuello C, Parrilla I, Gil MA, Vazquez JL, Vazquez JM, Roca J, Martinez EA, Fazeli A. 2012. Early developing pig embryos mediate their own environment in the maternal tract. PLoS One, 7:e33625.

Arnold JT, Kaufman DG, Seppala M, Lessey BA. 2001. Endometrial stromal cells regulate epithelial cell growth in vitro: a new co-culture model. Hum Reprod, 16:836-845.

Aumailley M, Timpl R. 1986. Attachment of cells to basement membrane collagen type IV. J Cell Biol, 103:1569-1575.

Briton-Jones C, Lok IH, Yuen PM, Chiu TT, Cheung LP, Haines C. 2002. Human oviductin mRNA expression is not maintained in oviduct mucosal cell culture. Fertil Steril, 77:576-580.

Briton-Jones C, Lok IH, Cheung CK, Chiu TT, Cheung LP, Haines C. 2004. Estradiol regulation of oviductin/oviduct-specific glycoprotein messenger ribonucleic acid expression in human oviduct mucosal cells in vitro. Fertil Steril, 81(suppl. 1):749-756.

Buck VU, Gellersen B, Leube RE, Classen-Linke I. 2015. Interaction of human trophoblast cells with glandlike endometrial spheroids: a model system for trophoblast invasion. Hum Reprod, 30:906-916.

Carvalho AV, Canon E, Jouneau L, Archilla C, Laffont L, Moroldo M, Ruffini S, Corbin E, Mermillod P, Duranthon V. 2017. Different co-culture 
systems have the same impact on bovine embryo transcriptome. Reproduction, 154:695-710.

Chen S, Einspanier R, Schoen J. 2013. In vitro mimicking of estrous cycle stages in porcine oviduct epithelium cells: estradiol and progesterone regulate differentiation, gene expression, and cellular function. Biol Reprod, 89:54. doi: 10.1095/biolreprod. 113.108829.

Chen S, Palma-Vera SE, Langhammer M, Galuska SP, Braun BC, Krause E, Lucas-Hahn A, Schoen J. 2017. An air-liquid interphase approach for modeling the early embryo-maternal contact zone. Sci Rep, 7:42298

Classen-Linke I, Kusche M, Knauthe R, Beier HM 1997. Establishment of a human endometrial cell culture system and characterization of its polarized hormone responsive epithelial cells. Cell Tissue Res, 287:171-185. Cordova A, Perreau C, Tsikis G, Reynaud K, Locatelli Y, Ponsart C, Mermillod P. 2012. Effect of bovine oviductal epithelial cell co-culture on early cleavage kinetics of bovine IVP embryos. Reprod Domest Anim, 47:447-448.

Cordova A, Perreau C, Uzbekova S, Ponsart C, Locatelli Y, Mermillod P. 2014. Development rate and gene expression of IVP bovine embryos cocultured with bovine oviduct epithelial cells at early or late stage of preimplantation development. Theriogenology, 81:1163-1173.

Coy P, Canovas S, Mondejar I, Saavedra MD, Romar R, Grullon L, Matas C, Aviles M. 2008 Oviduct-specific glycoprotein and heparin modulate sperm-zona pellucida interaction during fertilization and contribute to the control of polyspermy. Proc Natl Acad Sci USA, 105:15809-15814.

Cunha GR, Bigsby RM, Cooke PS, and Sugimura Y. 1985. Stromal-epithelial interactions in adult organs. Cell Differ, 17(3):137-148.

Danesh MS, Sharbati J, Einspanier R, Gabler C. 2016. mRNA expression pattern of selected candidate genes differs in bovine oviductal epithelial cells in vitro compared with the in vivo state and during cell culture passages. Reprod Biol Endocrinol, 14:44. doi: 10.1186/s12958-016-0176-7.

De Pauw IM, Van Soom A, Laevens H, Verberckmoes S, de Kruif A. 2002. Sperm binding to epithelial oviduct explants in bulls with different nonreturn rates investigated with a new in vitro model. Biol Reprod, 67:1073-1079.

Ellenbroek SI, Iden S, Collard JG. 2012. Cell polarity proteins and cancer. Semin Cancer Biol, 22:208-215.

Fazeli A. 2011. Maternal communication with gametes and embryo: a personal opinion. Reprod Domest Anim, 46(suppl. 2):75-78.

Fazeli A, Holt WV. 2016. Cross talk during the periconception period. Theriogenology, 86:438-442.

Ferraz M, Henning HHW, Costa PF, Malda J, Melchels FP, Wubbolts R, Stout TAE, Vos P, Gadella BM. 2017. Improved bovine embryo production in an oviduct-on-a-chip system: prevention of poly-spermic fertilization and parthenogenic activation. Lab Chip, 17:905-916.

Freeman DA, Woods GL, Vanderwall DK, Weber JA. 1992. Embryo-initiated oviductal transport in mares. J Reprod Fertil, 95:535-538

Garcia EV, Hamdi M, Barrera AD, SanchezCalabuig MJ, Gutierrez-Adan A, Rizos D. 2017. Bovine embryo-oviduct interaction in vitro reveals an early cross talk mediated by BMP signaling. Reproduction, 153:631-643.

Goff AK, Smith LC. 1998. Effect of steroid treatment of endometrial cells on blastocyst development during co-culture. Theriogenology, 49:1021-1030.

Gualtieri R, Mollo V, Braun S, Barbato V, Fiorentino I, Talevi R. 2012. Long-term viability and differentiation of bovine oviductal monolayers: bidimensional versus three-dimensional culture. Theriogenology 78:1456-1464.

Henry F, Eder S, Reynaud K, Schon J, Wibbelt G, Fontbonne A, Muller K. 2015. Seminal fluid promotes in vitro sperm-oviduct binding in the domestic cat (Felis catus). Theriogenology, 83:1373-1380.

Kessler M, Hoffmann K, Brinkmann V, Thieck O, Jackisch S, Toelle B, Berger H, Mollenkopf HJ, Mangler M, Sehouli J, Fotopoulou C, Meyer TF. 2015. The Notch and Wnt pathways regulate stemness and differentiation in human fallopian tube organoids. Nat Commun, 6:8989. doi: 10.1038/ncomms9989.

Kurita T, Cooke PS, and Cunha GR. 2001. Epithelialstromal tissue interaction in paramesonephric (Mullerian) epithelial differentiation. Dev Biol, 240(1):194-211.

Kurita T. 2011. Normal and abnormal epithelial differentiation in the female reproductive tract. Differentiation, 82:117-126.

Lee KF, Yao YQ, Kwok KL, Xu JS, Yeung WS. 2002. Early developing embryos affect the gene expression patterns in the mouse oviduct. Biochem Biophys Res Commun, 292:564-570.

Leese HJ, Hugentobler SA, Gray SM, Morris DG, Sturmey RG, Whitear SL, Sreenan JM. 2008. Female reproductive tract fluids: composition, mechanism of formation and potential role in the developmental origins of health and disease. Reprod Fertil Dev, 20:1-8. Levanon K, Ng V, Piao HY, Zhang Y, Chang MC, Roh MH, Kindelberger DW, Hirsch MS, Crum CP, Marto JA, Drapkin R. 2010. Primary ex vivo cultures of human fallopian tube epithelium as a model for serous ovarian carcinogenesis. Oncogene, 29:11031113.

Li SJ, Wang TS, Qin FN, Huang Z, Liang XH, Gao F, Song Z, Yang ZM. 2015. Differential regulation of receptivity in two uterine horns of a recipient mouse following asynchronous embryo transfer. Sci Rep, 5:15897. doi: 10.1038/srep15897.

Locatelli Y, Cognie Y, Vallet JC, Baril G, Verdier M, Poulin N, Legendre X, Mermillod P. 2005. Successful use of oviduct epithelial cell coculture for in vitro production of viable red deer (Cervus elaphus) embryos. Theriogenology, 64:1729-1739.

Maillo V, Gaora PO, Forde N, Besenfelder U, Havlicek V, Burns GW, Spencer TE, GutierrezAdan A, Lonergan P, Rizos D. 2015. Oviduct-embryo interactions in cattle: two-way traffic or a one-way street? Biol Reprod, 92:144. doi: 10.1095/biolreprod. 115.127969 .

Maillo V, Acuna OS, Aviles M, Lonergan P, Rizos D. 
2016. 74 The bovine embryo influences the proteome of the oviductal fluid. Reprod Fertil Dev, 29:144. (abstract).

MacKintosh SB, Serino LP, Iddon PD, Brown R, Conlan RS, Wright CJ, Maffeis TG, Raxworthy MJ, and Sheldon IM. 2015. A three-dimensional model of primary bovine endometrium using an electrospun scaffold. Biofabrication, 7(2):025010.

Miessen K, Sharbati S, Einspanier R, Schoen J. 2011. Modelling the porcine oviduct epithelium: a polarized in vitro system suitable for long-term cultivation. Theriogenology, 76:900-910.

Munson L, Wilkinson JE, Schlafer DH. 1990. Effects of substrata on the polarization of bovine endometrial epithelial cells in vitro. Cell Tissue Res, 261:155-161.

Olalekan SA, Burdette JE, Getsios S, Woodruff TK, Kim JJ. 2017. Development of a novel human recellularized endometrium that responds to a 28 day hormone treatment. Biol Reprod, 96:971-981.

Ostrowski LE, Nettesheim P. 1995. Inhibition of ciliated cell differentiation by fluid submersion. Exp Lung Res, 21:957-970.

Pierro E, Minici F, Alesiani O, Miceli F, Proto C, Screpanti I, Mancuso S, Lanzone A. 2001. Stromalepithelial interactions modulate estrogen responsiveness in normal human endometrium. Biol Reprod, 64:831838

Qi X, Qu Y, Nan Z, Jin Y, Zhao X, Wang A. 2012. Caprine endometrial stromal cells modulate the effects of steroid hormones on cytokine secretion by endometrial epithelial cells in vitro. Reprod Biol, 12:309-315.

Reischl J, Prelle K, Schol H, Neumuller C, Einspanier R, Sinowatz F, Wolf E. 1999. Factors affecting proliferation and dedifferentiation of primary bovine oviduct epithelial cells in vitro. Cell Tissue Res, 296:371-383.

Rizos D, Maillo V, Sanchez-Calabuig MJ, and Lonergan P. 2017. The consequences of maternalembryonic cross talk during the periconception period on subsequent embryonic development. $A d v \operatorname{Exp} \mathrm{Med}$ Biol, 1014:69-86.

Rottmayer R, Ulbrich SE, Kolle S, Prelle K, Neumueller C, Sinowatz F, Meyer HH, Wolf E, Hiendleder S. 2006. A bovine oviduct epithelial cell suspension culture system suitable for studying embryomaternal interactions: morphological and functional characterization. Reproduction, 132:637-648.

Schmaltz-Panneau B, Cordova A, Dhorne-Pollet S, Hennequet-Antier C, Uzbekova S, Martinot E, Doret S, Martin P, Mermillod P, Locatelli Y. 2014. Early bovine embryos regulate oviduct epithelial cell gene expression during in vitro co-culture. Anim Reprod Sci, 149:103-116.

Schmaltz-Panneau B, Locatelli Y, Uzbekova S, Perreau C, Mermillod P. 2015. Bovine oviduct epithelial cells dedifferentiate partly in culture, while maintaining their ability to improve early embryo development rate and quality. Reprod Domest Anim, 50:719-729.

Schoen J, Bondzio A, Topp K, Einspanier R. 2008 Establishment and characterization of an adherent pure epithelial cell line derived from the bovine oviduct. Theriogenology, 69:536-545.

Simintiras CA, Frohlich T, Sathyapalan T, Arnold GJ, Ulbrich SE, Leese HJ, Sturmey RG. 2016. Modelling oviduct fluid formation in vitro. Reproduction. doi:10.1530/REP-15-0508.

Simintiras CA, Sturmey RG. 2017. Genistein crosses the bioartificial oviduct and alters secretion composition. Reprod Toxicol, 71:63-70.

Smits K, De Coninck DI, Van NF, Govaere J, Van PM, Peelman L, Deforce D, and Van SA. 2016. The equine embryo influences immune-related gene expression in the oviduct. Biol Reprod, 94:36. doi: 10.1095/biolreprod.115.136432.

Turco MY, Gardner L, Hughes J, Cindrova-Davies T, Gomez MJ, Farrell L, Hollinshead M, Marsh SGE, Brosens JJ, Critchley HO, Simons BD, Hemberger M, Koo BK, Moffett A, Burton GJ. 2017. Long-term, hormone-responsive organoid cultures of human endometrium in a chemically defined medium. Nat Cell Biol, 19:568-577.

Umezu T, Tomooka Y. 2004. An evidence of stromal cell populations functionally linked with epithelial cell populations in the mouse oviduct. Zoolog Sci, 21:319326.

van der Weijden VA, Chen S, Bauersachs S, Ulbrich SE, Schoen J. 2017. Gene expression of bovine embryos developing at the air-liquid interface on oviductal epithelial cells (ALI-BOEC). Reprod Biol Endocrinol, 15:91. doi: 10.1186/s12958-017-0310-1.

Waberski D, Magnus F, Mendonca Ferreira F, Petrunkina AM, Weitze KF, Topfer-Petersen E. 2005. Importance of sperm-binding assays for fertility prognosis of porcine spermatozoa. Theriogenology, 63:470-484.

Wang H, Pilla F, Anderson S, Martinez-Escribano S, Herrer I, Moreno-Moya JM, Musti S, Bocca S, Oehninger S, Horcajadas JA. 2012. A novel model of human implantation: 3D endometrium-like culture system to study attachment of human trophoblast (Jar) cell spheroids. Mol Hum Reprod, 18:33-43.

Weber JA, Freeman DA, Vanderwall DK, Woods GL. 1991. Prostaglandin E2 secretion by oviductal transport-stage equine embryos. Biol Reprod, 45:540543.

Weimar CH, Post Uiterweer ED, Teklenburg G, Heijnen CJ, Macklon NS. 2013. In-vitro model systems for the study of human embryo-endometrium interactions. Reprod Biomed Online, 27:461-476.

Xiao S, Coppeta JR, Rogers HB, Isenberg BC, Zhu J, Olalekan SA, McKinnon KE, Dokic D, Rashedi AS, Haisenleder DJ, Malpani SS, Arnold-Murray CA, Chen K, Jiang M, Bai L, Nguyen CT, Zhang J, Laronda MM, Hope TJ, Maniar KP, Pavone ME, Avram MJ, Sefton EC, Getsios S, Burdette JE, Kim JJ, Borenstein JT, Woodruff TK. 2017. A microfluidic culture model of the human reproductive tract and 28-day menstrual cycle. Nat Commun, 8:14584. doi: $10.1038 /$ ncomms 14584 .

Zihni C, Mills C, Matter K, Balda MS. 2016. Tight junctions: from simple barriers to multifunctional molecular gates. Nat Rev Mol Cell Biol, 17:564-580. 